\title{
Eco Educadores: os agentes de transformação da realidade socioambiental da comunidade
}

\section{Patricia Antunes Russo \\ John Würdig \\ Guilherme Menezes \\ Douglas Ciecielski}

Curso de Engenharia Ambiental e Sanitária. UniRitter.

E-mails: focopati@gmail.com johnwurdig@yahoo.com.br

Recebido: 21 mar. 2017. Revisado: 24 mar. 2017 Aceito: 02 abr. 2017.

DOI: http://dx.doi.org/10.21674/2448-0479.34.753-763

\section{Resumo}

A Educação Ambiental abre caminho para um novo pensar em educação, e é fundamentalmente na universidade que se pode proporcionar um novo olhar para os conflitos ecológicos, sociais e culturais produzidos e vivenciados pela sociedade contemporânea. Assim, o projeto procurou desencadear um movimento significativo para a comunidade do entorno do Centro Universitário Ritter dos Reis/UniRitter - Zona Sul, através de quatro enfoques principais, que visaram desenvolver atividades voltadas para: a) a questão do reconhecimento da universidade como lugar onde se produz conhecimento tanto para a comunidade acadêmica, quanto para a comunidade ao seu entorno; b) formação e instrumentalização de estudantes da rede pública do entorno através de momentos de partilha de conhecimento técnico, experiências práticas e produtivas; e c) a importância da sua atuação como agente de mudança ambiental na 
sociedade em que está inserido e o quanto sua atuação pode influenciar na qualidade de vida de todos da comunidade. Desta forma, o este projeto visou atuar na formação de ECO EDUCADORES, que tem como desafio tornarem-se multiplicadores dos temas socioambientais, trabalhados nas oficinas de formação, assim contribuindo positivamente para uma mudança do cenário ambiental de sua comunidade.

Palavras-chave: Educação Ambiental. Conflitos. Extensão Universitária.

\section{Introdução}

Conforme Borja e Moraes (2006) a maioria das cidades brasileiras cresceram de forma desordenada e sem planejamento. Da mesma forma, muitas cidades no Brasil foram providas com precariedades na infraestrutura de acesso às questões básicas do saneamento ambiental, como: o abastecimento de água potável, a coleta e tratamento ambientalmente adequado dos resíduos sólidos, a coleta e tratamento do esgoto cloacal e as condições mínimas de drenagem urbana, sem ocasionar alagamentos ou enchentes, após um período de chuvas (BRITTO, 2004).

Assim, de acordo com Carneiro (2008) o cenário de degradação do meio ambiente das cidades brasileiras foi acentuado com a ocupação de áreas impróprias para a moradia, como as áreas de preservação permanente (topo de morro), local onde foram constituídas inúmeras ocupações irregulares. 
O Centro Universitário em que se realizou o presente projeto fica localizado na Zona Sul de Porto Alegre/RS, em uma área com graves problemas de urbanização, especialmente em relação a ocupação irregular de áreas de topo de morro. Neste contexto, a universidade possui importante papel na relação com a sua comunidade do entorno, colocando-se como agente de transformação desta realidade socioambiental. Além disto, esta instituição de ensino está comprometida com a inovação e o desenvolvimento sustentável da sociedade, tendo como objetivo quebrar os muros da instituição na busca soluções viáveis e concretas para a melhoria na qualidade de vida da população da comunidade da Vila Cruzeiro. Para o enfrentamento dos problemas socioambientais da comunidade do entorno da Universidade, a educação ambiental apresenta-se como um caminho para um novo pensar em educação e colabora de forma efetiva para a construção de uma rede de parceiros, a fim de colaborar na busca de soluções ambientais e tecnologias sociais.

Então, através do Edital de Extensão 01//2016 o curso de Engenharia Ambiental e Sanitária desta instituição de ensino efetivou o projeto Ecoeducadores, este tem como objetivo formar agentes ambientais para colaborar na transformação da realidade socioambiental da comunidade da Zona Sul. Em 2016 foram realizados encontros semanais, nas dependências do Centro Universitário, com 28 jovens de quatro escolas públicas do seu entorno, como resultado deste projeto foi desencadeando um movimento que formou uma forte rede entre: Universidade, Escolas, Comunidade, órgãos públicos, entidades de classe, ONG's e voluntários do projeto. 
O projeto trabalhou com três enfoques principais:

a) a questão do reconhecimento da universidade como lugar onde se produz conhecimento, tanto para a comunidade acadêmica, quanto para a comunidade ao seu entorno;

b) formação e instrumentalização de estudantes da rede pública do entorno através de momentos de partilha de conhecimento técnico, experiências práticas e produtivas;

c) a importância da sua atuação como agente de mudança ambiental na sociedade em que está inserido e o quanto sua atuação pode influenciar na qualidade de vida de todos da comunidade.

Tendo os seguintes objetivos:

1. Capacitar um grupo de estudantes do ensino fundamental da rede pública de ensino da comunidade do entorno da universidade, visando a formação de ECO Educadores, para atuarem na multiplicação de boas práticas socioambientais em sua comunidade.

2. Desenvolver junto à comunidade acadêmica, ou seja, os estudantes do curso de engenharia ambiental e sanitária e outras áreas afins, um momento de diálogo e formação na área ambiental, através dos relatos de experiências e compartilhamento de ideias da comunidade local participante do projeto.

\section{Material e Métodos}

Pensando a universidade como lugar de construção do conhecimento, especialmente através da transformação social do seu 
entorno, a metodologia do projeto alinha-se com seus objetivos e esta dividida em duas etapas, que serão apresentadas a seguir:

\section{$1^{\circ}$ Realização de Oficinas Socioambientais}

Com a realização dos encontros de formação, a criação e a conservação dos espaços livres foi possibilitada aos educandos que fortaleceram a sua consciência crítica e ecológica, particularmente através da participação de atividades que enfoquem a autonomia, a criatividade e o empoderamento dos jovens.

Com esta ação os estudantes de segundo ciclo/séries finais do ensino fundamental, que compreende a faixa etária de 12 a 15 anos, participaram de atividades práticas e dinâmicas, onde ocorrem momentos de aprendizado e reflexão sobre a relação de interdependência entre natureza e sociedade, procurando enfatizar o papel de cada um no cuidado do espaço que frequentam e como cada pessoa pode atuar na melhoria de sua qualidade de vida e de sua comunidade.

A cada encontro foram debatidas temáticas sociais e ambientais, estas foram trazidas pelos ECO Educadores, os encontros ocorreram semanalmente, com duração de três horas, sendo realizados nas dependências do campus universitário, possibilitando a integração da comunidade do entorno com a comunidade acadêmica.

\section{$2^{\circ}$ Realização do Diálogo Temático}

Este encontro ocorreu através da realização de um evento denominado Dialogo Temático, ele reuniu a comunidade acadêmica e todos os parceiros do Projeto, que compartilharam as demandas 
levantadas pelo diagnóstico ambiental realizado pelos ECO Educadores. O Dialogo Temático proporcionou uma excelente visibilidade do projeto, assim valorizando todo o trabalho que foi desenvolvido pelo grupo.

\section{Resultados e Discussões}

Cada uma das quatro escolas participantes do Projeto indicaram no mínimo seis estudantes para serem agentes ambientais (ECO Educadores). As atividades realizadas nos encontros semanais visam o empoderamento dos estudantes, para que assim, eles tenham condições de buscar ações colaborativas em parceria com os acadêmicos, professores e parceiros externos, para a solução dos problemas socioambientais da comunidade. Nos encontros o grupo desenvolveu a seguinte rotina: relato das suas atividades na semana, compartilhamento das ações do projeto e a partir destas trocas os próximos passos foram planejados, tendo como objetivo as melhorias ambientais na comunidade.

Para direcionar as ações, foi realizado um diagnóstico socioambiental, a partir da visão dos estudantes. Após os jovens realizaram entrevistas com moradores do bairro, e fizeram o uso de ferramentas de geoprocessamento, elaborando mapas e maquetes do território de atuação do Projeto. Além disso, foram realizadas oficinas sobre o correto gerenciamento dos resíduos sólidos urbanos e esclarecimentos sobre a legislação ambiental brasileira. Na Tabela 1 podemos verificar algumas informações sobre o comprometimento 
da comunidade com o correto gerenciamento dos resíduos sólidos, em especial com a coleta seletiva.

Tabela 1. Questionário aplicado na comunidade com as respostas obtidas.

\begin{tabular}{lllllllll}
\hline \multicolumn{2}{l}{$\begin{array}{l}\text { Você separa seus } \\
\text { resíduos? }\end{array}$} & \multicolumn{4}{l}{$\begin{array}{l}\text { Utiliza a coleta } \\
\text { seletiva? }\end{array}$} & \multicolumn{5}{c}{$\begin{array}{l}\text { O que você acha } \\
\text { da comunidade? }\end{array}$} \\
$\begin{array}{llllllll}\text { Sim } \\
\text { Não }\end{array}$ & 39 & $61 \%$ & Sim & 40 & $62 \%$ & Limpa & 13 & $20 \%$ \\
Às vezes & 22 & $34 \%$ & Não & 20 & $32 \%$ & Suja & 34 & $53 \%$ \\
\hline
\end{tabular}

Fonte: Projeto ECO Educadores 2016.

Visando compreender as consequências dos impactos ambientais da ação humana no território de atuação do projeto elaborou-se uma matriz de avaliação de impacto ambiental, nesta identificou-se os principais impactos ambientais existentes na comunidade do entorno da universidade, conforme evidenciado na Figura 01.

Figura 1: Matriz de identificação de Impactos Ambientais.

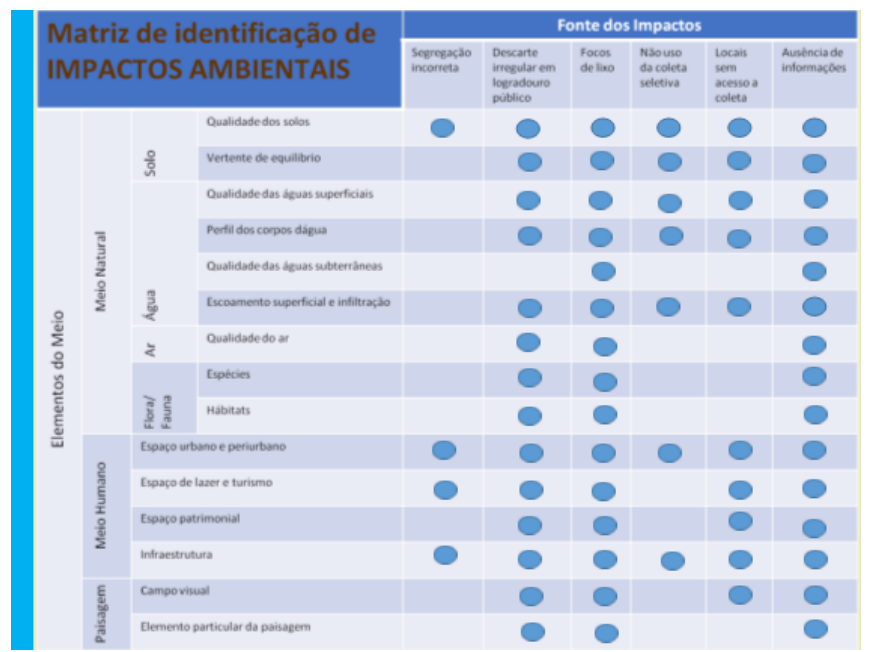

Fonte: Projeto ECO Educadores 2016 
Após a realização do diagnóstico ambiental pelos estudantes na comunidade, algumas demandas foram levantadas e colocadas em ordem de necessidade:

1. Melhorias na Gestão dos Resíduos sólidos urbanos, especialmente em relação à disposição correta dos resíduos sólidos, evitando assim a formação de pequenos lixões a céu aberto.

2. Criação e revitalização dos espaços de lazer, particularmente em relação às praças públicas que se encontram abandonadas e com acumulo de resíduos sólidos domiciliares.

Em relação ao $1^{\circ}$ Diálogo Temático do projeto ECO Educadores foi elaborado um plano de ação, com objetivos, metas e medidas para iniciar um planejamento para a reversão do cenário de disposição inadequada dos resíduos sólidos domiciliares na comunidade e a revitalização das praças, sendo estas ações os resultados esperados para o ano próximo ano de efetivação do projeto. A Figuras 2, 3, 4 e 5 mostram alguns dos momentos do projeto na comunidade. 

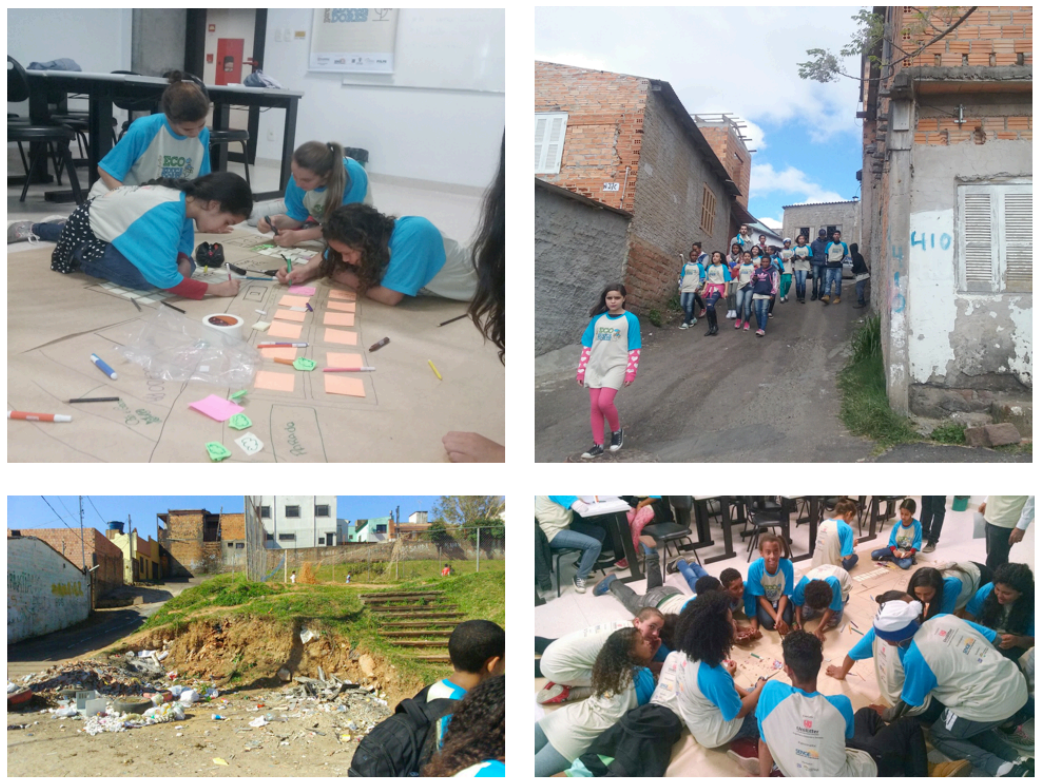

Fonte: Projeto ECO Educadores 2016

Figuras 02, 03, 04 e 05: Atuação do Projeto ECO Educadores.

\section{Conclusões}

No decorrer deste período foi possível notar que os encontros com os ECOS Educadores foram enriquecedores e possibilitaram a troca de experiências entre todos os integrantes, pois o projeto demonstrou ser uma excelente metodologia de construção de conhecimento e empoderamento dos estudantes na busca de soluções ambientais para a sua comunidade.

Em relação à formação dos agentes ambientais afirma-se que foi satisfatória a participação dos estudantes que estão em processo contínuo de construção do conhecimento na área ambiental. Os 
resultados do Projeto foram benéficos para a comunidade do entorno do Centro Universitário, pois os estudantes envolvidos encontraram no ECO Educadores uma oportunidade diferenciada para a sua formação, assim como os acadêmicos bolsistas de extensão tiveram a experiência de gerenciar um projeto de educação ambiental que esteve diretamente relacionado com a mudança de uma triste realidade ambiental, mas que encontrou no entusiasmo das crianças e jovens a esperança de um futuro melhor para a comunidade da Zona Sul.

\section{Referências}

ABES - Associação Brasileira de Engenharia Sanitária e Ambiental. 2016. Institucional. Disponível em: <http://abes-dn.org.br/>. Acesso em: 12 de dez. 2016.

AGENDA 21 GLOBAL. Declaração do Rio de Janeiro. Conferência das Nações Unidas sobre Meio Ambiente. Rio de Janeiro, RJ, 1992.

BORJA et al.. O acesso às ações e serviços de saneamento básico como um direito social. In: XII SILUBESA - Simpósio Luso Brasileiro de Engenharia Sanitária, 12., 2006, Figueira da Foz. Artigo. Figueira da Foz: Abes, 2006. p. 1 - 13. Disponível em: <https://goo.gl/NaMTsz>. Acesso em: 4 jan. 2017.

BORJA, P. C. \& MORAES, L. R. S., 2005. O Saneamento como um direito social. In: IX Exposição de Experiências Municipais em Saneamento - 35a Assembléia Nacional da Assemae. Belo Horizonte: Assemae. Disponível em: <https://goo.gl/vCi8Kp>. Acesso em: $13 \mathrm{dez}$. 2016. 
BRAGA, Benedito et al. Introdução à Engenharia Ambiental: o desafio do desenvolvimento sustentável. 2. ed. São Paulo: Pearson Prentice Hall, 2005. 315 p.

BRASIL, 2015, GEO Brasil - Recursos Hídricos: Resumo Executivo. Ministério Do Meio Ambiente; Agência Nacional De Águas; Programa das Nações Unidas para o Meio Ambiente. Brasília: MMA; ANA, 60 p.: il. (GEO Brasil Série Temática : GEO Brasil Recursos Hídricos)

BRASIL. Decreto $n^{\circ}$ 7.217, de 21 de junho de 2010. Regulamenta a Lei $\mathrm{n}^{\circ} 11.445$, de 5 de Janeiro de 2007, que estabelece diretrizes nacionais para o Saneamento Básico, e dá outras providências. Brasília, DF, Disponível em: <https://goo.gl/waHHp2>. Acesso em: 12 dez. 2016.

BRITTO, A. L. N. P., 2004. Gestão de Serviços de Saneamento em Áreas Metropolitanas: as alternativas existentes diante da necessidade de universalização dos serviços e preservação da qualidade ambiental. In: Anais II Encontro Anual da Associação Nacional de Pós Graduação e Pesquisa em Ambiente e Sociedade. Indaiatuba, São Paulo. Disponível em: <https://goo.gl/fo4TtA>. Acesso em 15 dez. 2016. 